\title{
Does impacted lower third molar exert a forwardly directed pressure? \\ Accepted: 2/10/2011
}

\begin{tabular}{c}
\hline Shehab Ahmed Hamad * \\
\hline Abstract
\end{tabular}

Background and objectives: Impacted lower third molar has been blamed for lower incisor crowding. The aim of this study was to measure the amount of pressure exerted by lower third molar.

Method: The study was conducted on 62 patients who underwent surgical removal of impacted lower third molars. The mean age of the subjects was 25.4 years with a range of 18 -37 years. Interdental frictional strength was measured between posterior teeth, before and one week after lower third molar removal, using $0.05 \mathrm{~mm}$ stainless steel strip and digital force gauge.

Results: No significant difference was noted in interdental frictional strength before and after lower third molar removal. The depth of impacted lower third molar and proximity of impacted tooth to the adjacent second molar has no significant influence on the interdental frictional strength.

Conclusion: Impacted lower third molar does not exert any significant force on the teeth and should not cause lower incisor crowding.

Keywords: impacted lower third molar, incisor crowding, frictional force.

\section{Introduction}

Lower arch crowding that develops or increases after establishment of the permanent dentition during the teenage period, best described as post- adolescent crowding, is a common clinical problem. The role of erupting third molars as a cause of such dental crowding has been the subject of controversy over the years. ${ }^{1}$ Dewey ${ }^{2}$ first described the role of third molar in causing crowding of the mandibular incisors in 1917. According to Dewey, " the mandibular third molar will become impacted (in some cases) due to lack of space ", while in other cases " it creates space for eruption by causing the lower anterior teeth to crowd ". This article set the stage for a controversy which still exists today. Although several studies have reported no relationship between erupting third molars and late anterior crowding, others state that there is a definite association. For example, Richardson ${ }^{3}$ concluded that lower third molar impaction is one of the causative factors because anterior crowding is present more often in patients with third molars than in subjects with these teeth absent. Other study by Šidlauskas \& Trakinienè ${ }^{4}$ evaluated the correlation between lower third molar presence and lower incisor crowding and reported that although difference between the groups were not statistically significant, a greater tendencies for crowding in the mandibular anterior teeth were expressed in patients who had lower third molars. Niedzielska ${ }^{5}$ reported that if sufficient space is not available for the lower third molars to erupt, these teeth exert forces on the other teeth, causing crowding. It is only when space is adequate that the tooth gains a normal position in the arch without causing any disadvantageous effect on the other teeth. To the contrary Ades et al. ${ }^{6}$ reported no differences in crowding in the

\footnotetext{
*Department of maxillofacial surgery, College of dentistry, Hawler Medical University, Erbil/Iraq.
} 
presence or absence of third molars and concluded that removal of third molars to alleviate anterior crowding may not be justified. In another study, Harradine et al. ${ }^{7}$ found no difference in lower labial segment irregularity between subjects in whom the third molars had been extracted than in subjects who did not undergo third molar extraction. Lindauer et al. ${ }^{8}$ found that smaller percentage of American orthodontists than maxillofacial surgeons $(58 \%$ vs. $78 \%$ ) believe that mandibular third molars produce anterior forces during eruption. Tüfekçi et al. ${ }^{9}$ concluded that most orthodontists in the United States and Sweden do believe that erupting lower third molars exert an anterior force; however, they also believe that these teeth "rarely" or "never" cause crowding. This study was performed to measure the interproximal force between posterior teeth before and after impacted lower third molar removal, in the assumption that mesially directed forces from impacted teeth would increase the proximal contact force between the teeth.

\section{Method}

The sample of the study included 62 patients who attended the department of oral and maxillofacial surgery, college of dentistry, Hawler medical university for removal of their impacted lower third molars. The study extended from October 2009 to January 2011. The subjects were 27 females and 35 males with an age range of 18-37 years (mean age 25.4 years). The inclusion criteria were: good general health, complete dentition, class I skeletal relationship, healthy periodontal conditions (i.e. probing pocket depth not more than $3 \mathrm{~mm}$ and absence of bleeding on probing). The exclusion criteria were: presence of gaps between teeth, proximal restorations, fixed bridge and periodontal disease. Subjects showing obvious signs of bruxism such as moderate to severe attrition were excluded as well as those with history of orthodontic treatment. At rest, contact tightness between the posterior teeth was considered appropriate if a
$0.05 \mathrm{~mm}$ stainless steel strip could be inserted with some resistance, but a 0.11 strip could not. ${ }^{10}$ The technique of measuring the proximal contact strength is based on the concept of frictional forces as described by Southard et al. ${ }^{11}$, Osborn ${ }^{12}$, Southard et al. ${ }^{13}$ The frictional force between teeth was recorded by a $0.05 \mathrm{~mm}$ thick stainless steel strip $(3 \times 25 \mathrm{~mm})$ which was slipped between the teeth and withdrawn with a digital force gauge (Figure 1).

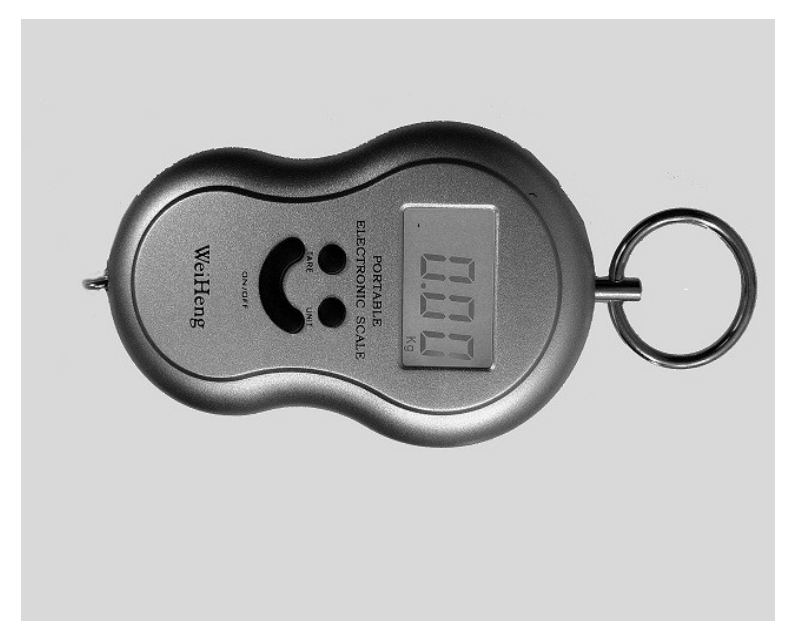

Figure 1: Digital force gauge.

The proximal contact strength ( PCS), in Newton $(N)$, between the teeth was related to the frictional force (Ff) that resisted withdrawal of the strip and the coefficient of dynamic friction $(P)$ between tooth enamel and the stainless steel strip by the following equation: $P C S=F f / 2 P$ [Newton] ${ }^{12}$. The coefficient of dynamic friction between enamel and stainless steel was estimated to be $0.145^{14}$. A constant of $2 \mathrm{P}$ is used instead of $\mathrm{P}$, since the strip slides along two teeth surfaces, each of which generates a frictional force against metal. The proximal contact strength was measured for mandibular posterior teeth, before and after removal of impacted lower third molars. The postoperative interdental frictional strength was measured one week after surgery when the patients returned for suture removal. The proximal contact strength was recorded between second molar-first molar, first molar-second 
premolar, second premolar-first premolar, first premolar-canine. The technique proceeded in a sequential order from posterior to anterior. The posterior teeth were only chosen for measuring interdental frictional force and anterior teeth were not in order to reduce the time of the procedure and maintain patient cooperation. The other reason for not adding anterior teeth in measurement is that the presence of even mild crowding would preclude the insertion of the stainless steel strip between the anterior teeth. Since posture and chewing may influence interdental frictional strength, all subjects were asked to sit down in upright position for at least one hour prior to measurement procedure and asked to refrain from eating at least one hour before the experiment ${ }^{15}$. Each subject was seated upright and asked to open his/her mouth widely. Before each measurement, the proximal contact areas were dried with an air syringe; because moisture may reduce frictional strength between the tooth and the metal strip. The strip was inserted between the teeth and withdrawn by hooking it to the digital force gauge. To standardize time-dependent displacements of the teeth due to the viscoelastic properties of the periodontal ligaments, the strip was removed immediately. Two measurements were made at each contact, and these were averaged to give a single proximal contact frictional force value. Before each measurement there was more than 2 minutes of rest to allow the proximal frictional strength to return to normal by viscoelastic relaxation of the periodontal ligaments. ${ }^{16}$ The interdental frictional strength was recorded in reference to the depth of impaction of lower third molars and proximity of the impacted tooth to the adjacent second molars. The impaction was considered partial when part of the tooth was erupted and completely impacted when no part was visible. With the aid of the periapical radiograph the proximity of the third molar to second molar was recorded as no contact relation when the third molar is not touching the second molar and contact relation when the third molar touches the adjacent second molar. The statistical evaluation of the data was performed using the software package SPSS version 12.1 (SPSS Inc., Chicago, USA). A paired t-test was used to evaluate the difference in proximal contact strength before and after lower third molar removal. Unpaired t-test was used to measure the significant effect of the depth of impaction and proximity of impacted tooth on the proximal contact strength between posterior teeth. The $P$ value of significance was considered at 0.05 .

\section{Results}

Of the 65 patients who underwent surgical removal of their impacted lower third molars, only three patients didn't attend for suture removal and measurements of postoperative proximal contact strength. The proximal contact strength between posterior teeth, before and one week after surgical removal of impacted lower third molars, is shown in Table (1) and Figure (2). The proximal contact strength showed a continuous decrease gradient in posterior -anterior direction both before and after surgery. The highest proximal contact strength was noted between the lower second molar-first molar contact area $(3.78 \pm 0.72 \mathrm{~N}$ before surgery and $3.65 \pm 0.82$ $\mathrm{N}$ after surgery). The lowest value of proximal contact strength was measured between the lower canine-first premolar contact area $(1.57 \pm 0.49 \mathrm{~N}$ before surgery and $1.47 \pm 0.64 \mathrm{~N}$ after surgery). No significant difference was noted in all posterior proximal contact strength measured before and after lower third molar removal $(P>0.05)$. Comparison of proximal contact strength between those with impacted lower third molars in contact with second molars and those without contact is shown in Table (2). No significant difference is noted between contact and non-contact cases $(P>0.05)$. Comparison of the proximal contact strength between those with partially impacted lower third molars and those with completely impacted lower third molar 
is shown in Table (3). No significant difference is noted between partial and

complete impacted cases $(P>0.05)$.

Table 1: Proximal contact strength between posterior teeth before and after lower third molar removal.

Proximal Contact Strength (Newton)

\begin{tabular}{cccccc}
\hline $\begin{array}{c}\text { Contact } \\
\text { region }\end{array}$ & $\begin{array}{c}\text { Before surgery } \\
\text { Mean } \pm \text { SD }\end{array}$ & $\begin{array}{c}\text { After surgery } \\
\text { Mean } \pm \text { SD }\end{array}$ & $\begin{array}{c}\text { Difference } \\
\text { Mean } \pm \text { SD }\end{array}$ & T-value & $\boldsymbol{P}$-value \\
\hline $1 \mathrm{M}-2 \mathrm{M}$ & $3.78 \pm 0.72$ & $3.65 \pm 0.82$ & $0.13 \pm 0.52$ & 1.945 & $>0.05^{*}$ \\
$1 \mathrm{M}-2 \mathrm{P}$ & $2.58 \pm 0.86$ & $2.42 \pm 0.67$ & $0.16 \pm 0.63$ & 1.999 & $>0.05$ \\
$2 \mathrm{P}-1 \mathrm{P}$ & $2.12 \pm 0.68$ & $2.00 \pm 0.72$ & $0.12 \pm 0.48$ & 1.969 & $>0.05$ \\
$1 \mathrm{P}-\mathrm{C}$ & $1.57 \pm 0.49$ & $1.47 \pm 0.64$ & $0.10 \pm 0.40$ & 1.969 & $>0.05$
\end{tabular}

* Not significant, M=Molar, $\mathrm{P}=$ Premolar, $\mathrm{C}=$ Canine.

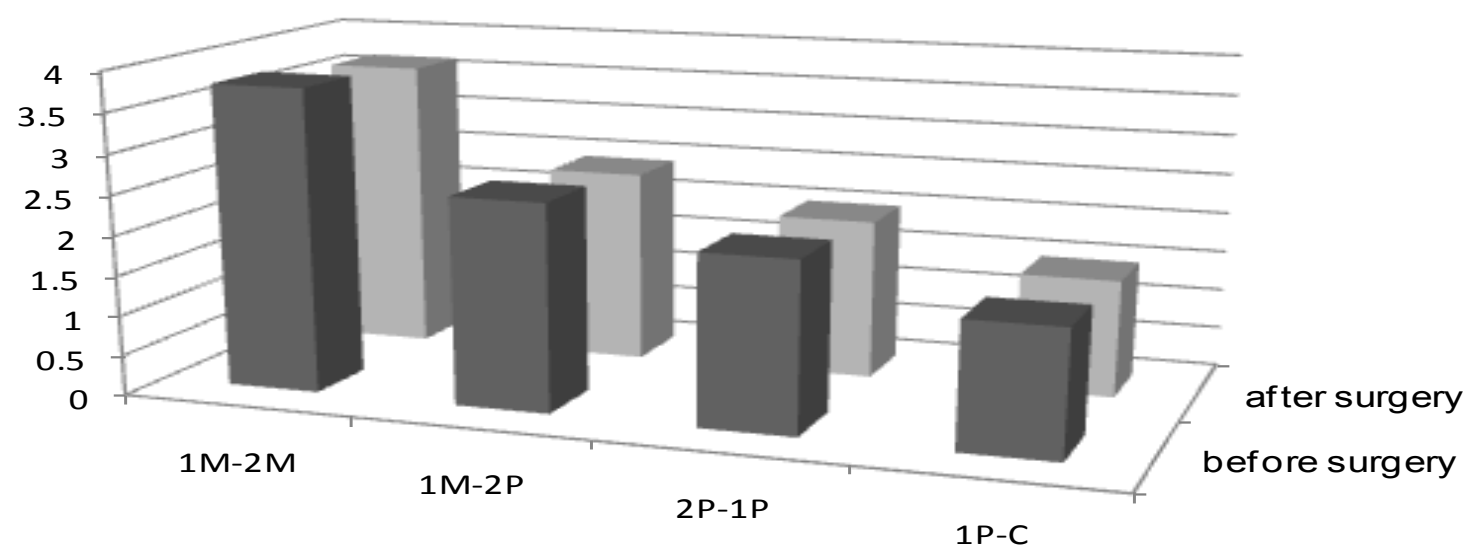

Figure 2: Proximal contact strength between posterior teeth before and after impacted lower third molar removal.

Table 2: Proximal contact strength with contact and no contact between impacted lower third molar and adjacent second molar.

\section{Proximal contact strength (Newton)}

\begin{tabular}{lcccc}
\hline $\begin{array}{c}\text { Contact } \\
\text { region }\end{array}$ & $\begin{array}{c}\text { Contact with second } \\
\text { molar (Mean } \pm \text { SD) }\end{array}$ & $\begin{array}{c}\text { No contact with second } \\
\text { molar (Mean } \pm \text { SD) }\end{array}$ & T-value & $P$-value \\
\hline $1 \mathrm{M}-2 \mathrm{M}$ & $4.10 \pm 0.83$ & $3.67 \pm 0.75$ & 1.884 & $>0.05^{*}$ \\
$1 \mathrm{M}-2 \mathrm{P}$ & $2.70 \pm 0.58$ & $2.48 \pm 0.42$ & 1.604 & $>0.05$ \\
$2 \mathrm{P}-1 \mathrm{P}$ & $2.23 \pm 0.52$ & $1.92 \pm 0.69$ & 1.598 & $>0.05$ \\
$1 \mathrm{P}-\mathrm{C}$ & $1.70 \pm 0.42$ & $1.45 \pm 0.57$ & 1.565 & $>0.05$ \\
& & & & \\
${ }^{*}$ Not significant, M=Molar, $\mathrm{P}=$ Premolar, $\mathrm{C}=$ Canine. & & \\
\hline
\end{tabular}


Table 3: Proximal contact strength with partial and complete lower third molar impaction.

Proximal contact strength (Newton)

\begin{tabular}{ccccc}
\hline $\begin{array}{c}\text { Contact } \\
\text { region }\end{array}$ & $\begin{array}{c}\text { Complete impaction } \\
\text { (Mean } \pm \text { SD) }\end{array}$ & $\begin{array}{c}\text { Partial impaction } \\
\text { (Mean } \pm \text { SD) }\end{array}$ & T-value & $\boldsymbol{P}$-value \\
\hline $1 \mathrm{M}-2 \mathrm{M}$ & $4.02 \pm 0.72$ & $3.68 \pm 0.87$ & 1.539 & $>0.05^{*}$ \\
$1 \mathrm{M}-2 \mathrm{P}$ & $2.80 \pm 0.54$ & $2.42 \pm 0.78$ & 1.997 & $>0.05$ \\
$2 \mathrm{P}-1 \mathrm{P}$ & $2.31 \pm 0.69$ & $1.97 \pm 0.75$ & 1.734 & $>0.05$ \\
$1 \mathrm{P}-\mathrm{C}$ & $1.68 \pm 0.53$ & $1.39 \pm 0.62$ & 1.827 & $>0.05$
\end{tabular}

* Not significant, $M=$ Molar, $\mathrm{P}=$ Premolar, $\mathrm{C}=$ Canine.

\section{Discussion}

Considerable controversy exists reporting the role of the third molar in mandibular incisor crowding. Historically, it has been assumed that the push of the third molar resulted in mandibular incisor crowding. ${ }^{17}$ The results of the present study clearly demonstrate that if unerupted lower third molars do generate a mesially directed force, detected by proximal contact frictional strength, it was of very little magnitude so that the difference before and after surgery was not significant. The results of the present study comes in accordance with that of Southard et al. ${ }^{13}$, who measured the interproximal force of the sides on which third molars were extracted and the opposite sides where the third molars were not extracted, concluding that there was no significant difference between them. If there was any significant forward push form impacted third molar, it could be detected by measuring the proximal frictional contact force. Fuhrman et al. ${ }^{18}$ applied a mesially directed forces of 1-5 Newton to the distal surface of the second molars and found that the frictional forces measured increased in proportion to the distally applied forces. The findings of the present study disprove the concept that link the lower third molar impaction with late lower incisor crowding. ${ }^{19-21}$ The forces detected at the proximal contact regions between posterior teeth may be attributed to another forces other than that of erupting third molars. The most notable one is the anterior component of occlusal forces ${ }^{11}$.In support to our findings, Proffit ${ }^{22}$ noted that erupting teeth create a pressure of only $5-10$ grams; so it's difficult to imagine how a pressure of that light magnitude exerted at the posterior part of the arch, could cause crowding in the anterior part of the arch. One may argue that the subjects in the study have completely developed roots and have passed the eruptive stage to generate any significant force. However, the eruptive mechanism is a dynamic process and remains intact even after a tooth has reached a functional occlusal state; hence, if a third molar exerts a mesially directed pressure it should have been detected by measuring the interdental proximal strength. ${ }^{23}$ In our study the proximal contact strength is not significantly influenced by the depth of impaction and proximity of the impacted tooth to the adjacent lower second molar. The results comes in agreement with those of Okazak $^{24}$ who found that the total interproximal contact forces of subjects with a third molar in contact with the second molar ranged from 50-143 gram force (gf) with a mean of $91 \mathrm{gf}$, and the total interproximal force of the other subjects with no contact between third and second molar ranged from 30-136 gf (mean of 81 
gf); with the difference being insignificant.

\section{Conclusions}

Impacted lower third molar does not exert any significant force on the teeth and should not cause lower incisor crowding. Therefore, removal of impacted lower third molars for preventing or relieving lower incisor crowding may be unjustified.

\section{References}

1. Alzoghaibi I: The development of lower third molars and lower incisor crowding-is there a relationship? Master thesis, Stockholm; Karolinska Institute.2003

2. Dewey M: Third molars in relation to malocclusion. Int. J. Orthod. 1917; 3:29-533.

3. Richardson ME: The role of the third molar in the cause of late lower arch crowding: a review. Am. J. Orthod. 1989; 95:79-83.

4. Šidlauskas A \& Trakinienè G: Effect of the lower third molars on the lower dental arch crowding. Stomatologia 2006; 8:80-84.

5. Niedzielska I: Third molar influence on dental arch crowding. Eur. J. Orthod. 2005; 27; 518-523.

6. Ades AG, Joondeph DR, Little RM, Chapko MK: A long term study of the relationship of third molars to changes in the mandibular dental arch. Am. J. Orthod. Dentofac. Orthop; 1990:97:323-335.

7. Harradine NWT: The effect of extraction of third molars on late lower incisor crowding: A randomized controlled trial. Br. J. Orthod. 1998; 25:117122.

8. Lindauer SJ, Laskin DM, Tüfekçi E, Taylor RS, Chusing BJ, Best A. M.: Orthodontists' and surgeons' opinions on the role of third molars as a cause of dental crowding. Am. J. Orthod. Dentofac. Orthop. 2007; 132:43-48.

9. Tüfekçi E, Svensk D, Kallunki , Huggare J, Lindauer SJ, Laskin DM: Opinions of American and Swedish orthodontists about the role of erupting third molars as a cause of dental crowding. Angle Orthod. 2009; 79:1139-1142.

10. Kasahara $K$, Miura $H$, Kuriyama $M$, Kato $H$, Hasegawa $S$ : Observations of interproximal contact relations during clenching. Int. J. Prosthod. 2000; 13:289-294.

11. Southard TE, Behrents RG, Tolley EA: The anterior component of occlusal force. Part I: measurement and distribution. Am. J. Orthod. Dentofac. Orthop. 1989; 96:493-500.

12. Osborn JW: An investigation into the interproximal forces occurring between the teeth of the same arch during clenching the jaws. Arch. Oral Biol. 1961; 5:202-211.

13. Southard TE, Southard KA, and Weeda LW: Mesial force form unerupted third molars. Am. J. Orthod. Dentofac. Orthop. 1991; 99:220-225.
14. Southard TE: A study of the anterior component of occlusal forces, Master's thesis, Memphis: University of Tennessee, 1988:p.140.

15. Kim HS, Na HJ, Kim HJ, Kang DW, Oh SH: Evaluation of proximal contact strength by postural changes. J. Adv. Prosthod. 2009; 1:118123.

16. Kim $\mathrm{KH}$, Jung JH, Kim $\mathrm{HJ}$, Chung $\mathrm{CH}$, Oh $\mathrm{SH}$ : Evaluation of proximal tooth contact in permanent dentition. J. Korean Acad. Prosthod. 2008; 46:553-559.

17. Sargiss G, Epstein J, Kapoor S, Morgenstem T, Epstein M: Third molars and lower incisor crowding. Orthod. Update 2008; 3(2):1-4.

18. Fuhrmann R., Grave C., Diedrich P.: In vitro evaluation of a measurement method to analyze the interdental, mesially directed force. J. Orthofac. Orthop. 1998; 59(6):362-370.

19. Al-Sayagh NM, Mohammad AA, Ismail LM: The relationship of the third molar to the anterior dental crowding. Al-Radfidain Dental J. 2004; 4 (1):1-9.

20. Richardson ME: Orthodontic implications of lower third molar development. Dental Update 1996; 23:96-102.

21. Fuhrmann R, Grave C, Dierdich P: Perioperative progress check of interdental forces following extraction of third molars. J. Orofac. Orthop. 2000; 61(3):155-167.

22. Proffit WR, Prewitt JR, Baik HS and Lee CF: Video Microscope Observations of Human Premolar Eruption. J. Dent. Res. 1991; 70: 15-18.

23. Proffit WR, Fields HW, Sarver DM: Contemporary orthodontics. $4^{\text {th }}$ ed. St. Louis, USA: Mosby Company; 2007. P. 148. 